\title{
O ACOMPANHAMENTO DA GERMINAÇÃO E DO CRESCIMENTO DAS PLANTAS NA EDUCAÇÃO INFANTIL
}

\author{
FOLLOW-UP OF GERMINATION AND GROWTH OF PLANTS \\ IN CHILD EDUCATION
}

\section{EL MONITOREO DE LA GERMINACIÓN Y CRECIMIENTO DE LAS PLANTAS EN LA EDUCACIÓN INFANTIL}

\author{
Giovanni Genehr ${ }^{1}$ \\ https://orcid.org/0000-0003-4093-699X
}

\begin{abstract}
${ }^{1}$ E. M. E. I. Antônio Leite e E. M. E. F. Álvaro Luis Nunes, São Leopoldo, RS - Brasil. E-mail: ggenehr@ymail.com.
\end{abstract}

\section{Resumo}

Este relato de experiência apresenta um projeto desenvolvido com crianças de 5 anos em uma escola de Educação Infantil de São Leopoldo (RS). O intuito da pesquisa foi identificar as aprendizagens de crianças da Educação Infantil resultantes de um projeto educacional que envolveu o acompanhamento da germinação e do crescimento das plantas, usando fotografia e vídeo como ferramentas de documentação do processo. A pesquisa teve como metodologia a análise documental. Para realizá-la, foram utilizados os materiais de sistematização do projeto: um vídeo produzido no Movie Maker e um informativo feito no Publisher. Como referencial teórico foram usados estudos sobre Educação Infantil e tecnologias digitais na Educação. O estudo demonstrou que as crianças participantes do projeto, ao considerarem os vídeos produções que serão assistidas por outras pessoas, buscaram estabelecer uma relação com o público. Além disso, foi possível perceber que as tecnologias digitais colaboraram no registro e na divulgação dos acontecimentos, possibilitando que as crianças analisassem o que observavam. Nesse sentido, elas potencializam as aprendizagens, principalmente ao possibilitarem que a documentação do processo de desenvolvimento das ações pedagógicas seja feita por meio do olhar infantil.

Palavras-chave: Projeto Educacional. Meio Ambiente. Experimentação. Educação Infantil.

\begin{abstract}
This experience report presents a project developed with 5 years old children in a school of Early Childhood Education of São Leopoldo (RS). The aim of the research was to identify the learning of early childhood children resulting from an educational project that involved the follow-up of germination and plant growth, using photography and video as tools for documenting the process. The research had as methodology the documental analysis. To this
\end{abstract}


end, the project systematization materials were used: a video produced in Movie Maker and an informative made in Publisher. As a theoretical reference, studies on Early Childhood Education and digital technologies in Education have been used. The study showed that the children participating in the project, considering the videos as productions that will be watched by other people, sought to establish a relationship with the public. In addition, it was possible to perceive that the digital technologies collaborated in the recording and dissemination of events, allowing the children to analyze what they observed. In this sense, they potentiate learning, especially by enabling the documentation of the process of development of pedagogical actions to be done through the child's point of view.

Keywords: Educational Project. Environment. Experimentation. Child Education.

\section{Resumen}

Este informe de experiencia presenta un proyecto desarrollado con niños de 5 años en una escuela de Educación Infantil de São Leopoldo (RS). El objetivo de la investigación fue identificar el aprendizaje de los niños de la Educación Infantil resultantes de un proyecto educativo que implicó monitorear la germinación y el crecimiento de las plantas, utilizando la fotografía y el video como herramientas para documentar el proceso. La investigación tuvo como metodología el análisis documental. Para realizarla, se utilizaron los materiales de sistematización del proyecto: un vídeo producido en el Movie Maker y un informativo hecho en Publisher. Como referencial teórico se utilizaron estudios sobre Educación Infantil y tecnologías digitales en la Educación. El estudio demostró que los niños participantes del proyecto, al considerar los vídeos producciones que serán asistidas por otras personas, buscaron establecer una relación con el público. Además, ha sido posible percibir que las tecnologías digitales colaboraron en el registro y difusión de los acontecimientos, posibilitando a los niños analizar lo que estaban observando. En ese sentido, ellos potencian los aprendizajes, principalmente al posibilitar que la documentación del proceso de desarrollo de las acciones pedagógicas se haga por medio de la mirada infantil.

Palabras clave: Proyecto Educativo. Medio Ambiente. Experimentación. Educación Infantil.

\section{Introdução}

A escola, como parte integrante da sociedade, passou por reconfigurações após a entrada das tecnologias digitais em seus espaços. Nesse cenário, em que elas estão cada vez mais presentes no cotidiano, não somos apenas receptores, mas também produtores de informações. Com base nisso, refletir sobre suas potencialidades para o desenvolvimento de propostas pedagógicas possibilita que essas tecnologias sejam inseridas de forma planejada e intencional nas intervenções docentes, qualificando os processos de ensino e de aprendizagem.

A partir dessas considerações iniciais, percebe-se a complexidade envolvida nesse exercício de reflexão sobre os usos das tecnologias digitais nas escolas. Este relato apresenta experiências vivenciadas durante o desenvolvimento de um projeto em uma escola municipal 
de Educação Infantil de São Leopoldo (RS) com 16 crianças de 5 anos. O projeto, que tinha como objetivo principal despertar a curiosidade e o interesse sobre o desenvolvimento das plantas por meio da produção de fotografias e vídeos, foi elaborado e executado no decorrer do curso de Especialização em Tecnologias da Informação e Comunicação na Educação. Durante o período em que foi planejado, buscou-se a articulação da temática "meio ambiente", que é trabalhada na escola, com o uso educativo das tecnologias digitais, que é o foco do curso.

As ações executadas na escola tinham dois objetivos específicos: identificar as diferenças e semelhanças existentes no desenvolvimento das plantas por meio do olhar atento durante a captação de imagens e reconhecer a biodiversidade com o auxílio de registros fotográficos e de vídeos. Para atingi-los, utilizou-se a metodologia "unidade de aprendizagem". Ao se optar pelo trabalho com essa metodologia, há inúmeras possibilidades de caminhos a construir. Na execução do projeto, não foram seguidos passos definidos previamente de forma inflexível, pois não havia uma sequência única e fechada a ser reproduzida. Uma unidade de aprendizagem "[...] se reestrutura, se amplia, se reduz, se transforma" (GALIAZZI, s/d, p. 2). Sendo assim, as crianças estavam envolvidas na compreensão do que estava sendo trabalhado, expressando opiniões e hipóteses acerca do que observavam e executavam. Seus conhecimentos prévios eram respeitados, valorizados e ampliados. Conforme Freschi e Ramos (2009, p. 157158), “A UA [Unidade de Aprendizagem] é um processo organizado, porém flexível, que possibilita a reconstrução do conhecimento dos educandos, considerando seus interesses, desejos e necessidades". Cabe destacar, ainda, que o trabalho coletivo, bastante enfatizado nessa metodologia, favoreceu a construção de conhecimentos em grupo, permitindo que as crianças aprendessem umas com as outras. A turma esteve imersa em momentos de elaboração coletiva e individual, em que as aprendizagens eram explicitadas e, em muitas circunstâncias, ocorria o diálogo. Nesse contexto, a autoria foi estimulada.

Nesse projeto, as crianças plantaram sementes de alface, rabanete e girassol. Enquanto acompanharam o desenvolvimento das plantas, produziram fotografias e gravaram vídeos. A partir desses materiais, foi organizado um vídeo ${ }^{1}$ que sintetizou as ações realizadas. Além disso, foi feito um informativo utilizando um software para a criação de publicações de comunicação visual $^{2}$ que, assim como o vídeo, demonstrou algumas aprendizagens construídas. Essas ações serão discutidas com mais detalhamento posteriormente.

\footnotetext{
${ }^{1}$ Utilizou-se o editor de vídeos Movie Maker (Microsoft).

${ }^{2}$ Publisher (Microsoft).
} 
Nas análises que serão feitas a seguir, busco responder à seguinte questão sobre a produção de vídeos e de fotografias: como as crianças participantes do projeto percebem o uso das tecnologias? Além disso, pretendo responder ao seguinte questionamento: quais as potencialidades das tecnologias digitais para trabalhar a experimentação investigativa com crianças da Educação Infantil? A análise dos vídeos gravados pelas crianças e do informativo produzido fornecerá subsídios para se compreenderem essas indagações, assim como permitirá abordar os conhecimentos científicos relacionados com a germinação e o crescimento das plantas construídos pela turma. Para demonstrar os resultados da pesquisa, algumas falas transcritas e considerações das crianças serão apresentadas. A partir disso, serão expostas reflexões sobre os aspectos evidenciados na pesquisa. $\mathrm{O}$ objetivo deste estudo, portanto, foi identificar as aprendizagens de crianças da Educação Infantil resultantes de um projeto educacional que envolveu o acompanhamento da germinação e do crescimento das plantas, usando fotografia e vídeo como ferramentas de documentação do processo. A pesquisa, de caráter qualitativo, teve como metodologia a análise documental. Convém ressaltar que o contato direto com as crianças durante o desenvolvimento das ações do projeto influenciou o exercício analítico, uma vez que a produção dos documentos analisados teve o meu acompanhamento como professor da turma.

Nas próximas seções, serão discutidas ideias sobre Educação Infantil e tecnologias na Educação em consonância com autores que abordam essas temáticas.

\section{Educação Infantil e suas especificidades}

Ao se trabalhar com crianças, a reflexão sobre o conceito de infância é um aspecto fundamental, visto que interfere na condução dos processos de ensino e de aprendizagem. Segundo Horn (2012, p. 14-15),

Pesquisas recentes estão mostrando que as crianças não são apenas alunos, uma vez que a escola representa apenas uma parte de suas vidas; que as crianças não são seres pré-sociais, objetos manipuláveis, vítimas passivas, seres culturalmente neutros, subordinados a modos de dominação e controle social; que elas são produtoras de culturas, não sendo apenas consumidoras da cultura dos adultos; que são atores sociais, dotados de capacidades de ação e culturalmente criativos, participando de seus processos de socialização, transformando a sociedade e sendo também transformados por ela. 
Com base nesse entendimento, pode-se afirmar que as crianças se expressam de muitos modos, usando diferentes linguagens e, nesses movimentos, inúmeras vezes mudam os rumos das intervenções pedagógicas. É indispensável, portanto, o respeito às particularidades da Educação Infantil, contemplando seus tempos e espaços e mantendo a indissociabilidade entre educar e cuidar. Conforme o artigo $4^{\circ}$ das Diretrizes Curriculares Nacionais para a Educação Infantil,

\begin{abstract}
As propostas pedagógicas da Educação Infantil deverão considerar que a criança, centro do planejamento curricular, é sujeito histórico e de direitos que, nas interações, relações e práticas cotidianas que vivencia, constrói sua identidade pessoal e coletiva, brinca, imagina, fantasia, deseja, aprende, observa, experimenta, narra, questiona e constrói sentidos sobre a natureza e a sociedade, produzindo cultura. (BRASIL, 2013, p. 97.)
\end{abstract}

Devido a esses aspectos, o exercício de escuta e olhar sensível favorece a adaptação do planejamento. Por isso, a implementação de propostas que possibilitem a exploração e o encantamento com as descobertas permite a impregnação de sentidos no cotidiano das crianças, possibilitando a aprendizagem de maneira espontânea. Conforme Horn (2012, p. 19), "[...] a escola de Educação Infantil constitui-se em um espaço onde saberes são partilhados, criados, manifestados, reproduzidos e ressignificados durante as brincadeiras, as conversas, as negociações e as disputas". Assim sendo, é estabelecido um processo de compartilhamento, ampliação e construção de conhecimentos nas interações ocorridas na escola. Segundo Oliveira (2010, p. 6), “À medida que o grupo de crianças interage, são construídas as culturas infantis". É importante, por isso, que elas possam resolver seus anseios e conflitos nas relações estabelecidas com seus pares, desenvolvendo a autonomia.

Dessa forma, as propostas do projeto prezaram pelo respeito às contribuições dadas por cada criança. Além disso, era preciso que elas fossem desafiadas e, da mesma forma, isso se constituía em um desafio para mim, enquanto professor. No exercício da docência na Educação Infantil, "É preciso desautomatizar nossa percepção das coisas, convertendo em problema tudo o que já sabemos, convertendo em desconhecido aquilo que cremos saber” (HORN, 2012, p. 19). Nesse processo, os saberes docentes estão sempre em constante ressignificação. Conforme Pimenta (1997, p. 6), “[...] professorar não é uma atividade burocrática para a qual se adquirem conhecimentos e habilidades técnico-mecânicas", por essa razão os saberes e a identidade profissional estão sempre em construção. 
Devido às especificidades da Educação Infantil, antes de iniciar o projeto, as crianças fizeram uma caminhada no entorno da escola para fotografar o que desejassem. Enquanto andávamos pelas ruas, elas solicitavam a câmera quando desejavam fazer uma fotografia. Como já era esperado que gostariam de fazer essa atividade, houve uma combinação prévia de que deveriam fazer apenas uma fotografia devido à quantidade de crianças e ao tempo que seria empregado. Essa atividade foi realizada para que tivessem contato com a câmera fotográfica que seria utilizada durante o desenvolvimento do projeto. Foi possível perceber que elas apresentaram dificuldade em manusear o equipamento por não apresentar um visor grande, assim como a luz do sol prejudicava a visualização da imagem a ser capturada. Cabe mencionar que algumas crianças colocaram os dedos na frente da lente.

A partir da observação desse contato inicial com o equipamento, foram elaboradas algumas orientações para que as crianças pudessem usar a câmera com mais precisão. A discussão sobre esses aspectos relacionados com o uso dos recursos tecnológicos está presente na próxima seção.

\section{Fotografia e vídeo na produção de registros de aprendizagem}

O uso das tecnologias digitais tem sido desafiador em diversos espaços escolares, pois perpassa desde a falta de formação dos professores até a infraestrutura precária. Nesses contextos, ainda se faz necessário que seu potencial seja reconhecido e que sejam utilizadas de forma coerente com o mundo globalizado em que vivemos. Nessa perspectiva, "As tecnologias e mídias digitais e suas linguagens específicas provenientes do mundo contemporâneo precisam ser compreendidas e apreendidas pelos professores no cotidiano da escola" (MARQUETI; SÁ, 2017, p. 179). Por estarem tão presentes na sociedade, podem ser integradas ao currículo de modo a favorecer o alcance de objetivos educacionais. A articulação entre os objetivos, as metodologias, os recursos tecnológicos e a avaliação é, portanto, essencial para que se produzam resultados positivos na aprendizagem.

No projeto desenvolvido, a produção de fotografias e a gravação de vídeos foram os meios de documentação usados pelas crianças. A fotografia é uma forma de registro de fácil acesso, devido, principalmente, à disseminação dos smartphones. Além de ser utilizada pelos professores para fins de documentação e divulgação do trabalho pedagógico, pode ser possibilitado o protagonismo das crianças no uso das câmeras com propósitos educacionais. A 
fotografia é considerada um documento que transmite e produz informações (BOCCATO; FUGITA, 2006). Conforme Boccato e Fugita (2006, p. 86), “A palavra fotografia tem origem no idioma grego e significa escrever com a luz (foto = luz e grafia = escrita). Nesse sentido, o significado da própria palavra já a nomeia como documento”. Essa mídia, usada para diversas finalidades, esteve presente no projeto realizado como uma forma de registro do desenvolvimento das plantas. As crianças capturaram as imagens e puderam revê-las, assim como outras pessoas as acessaram quando a divulgação do projeto foi realizada.

A gravação de vídeos pela turma foi outra prática recorrente que colaborou na construção e no registro de conhecimentos. Conforme Cordeiro e Almeida (2012, p. 209), o vídeo é uma "[...] linguagem multifacetada e híbrida, que permite a expressão de mensagens, sentimentos e ideias por intermédio de diversos recursos".

Algo que se destacou na gravação dos vídeos feitos pelas crianças foi a maneira como elas se portaram: costumavam iniciar cumprimentando e encerrar se despedindo. "Oi, gente!" e “Oi, galerinha!" são exemplos. Um menino começou um de seus vídeos dizendo "Oi, galerinha do Youtube!" e também fez agradecimentos ao final de uma de suas gravações: "Eu queria agradecer a todos por verem o meu vídeo". Eu não havia trabalhado com a turma essas questões de comunicação. Isso me permitiu deduzir que recursos multimídia fazem parte do cotidiano delas e, portanto, apresentam conhecimentos prévios que qualificaram as ações do projeto. Além disso, ao acompanharem os momentos em que seus colegas eram filmados, puderam aprender e, posteriormente, reproduzir alguns de seus comportamentos. É possível inferir, ainda, que as crianças participantes apresentam a compreensão de que vídeos costumam ser produzidos para serem visualizados por outras pessoas. Durante as gravações, em vários momentos, foi estabelecida uma comunicação com o público: “Olha aqui, pessoal! [...] Tão vendo?", “Entendeu, pessoal?", entre outros exemplos que poderiam ser citados. Inclusive, fizeram movimentos como acenar com as mãos. Por isso, segundo Oliveira (2010, p. 5),

\footnotetext{
A atividade da criança não se limita à passiva incorporação de elementos da cultura, mas ela afirma sua singularidade atribuindo sentidos à sua experiência através de diferentes linguagens, como meio para seu desenvolvimento em diversos aspectos (afetivos, cognitivos, motores e sociais). Assim a criança busca compreender o mundo e a si mesma, testando de alguma forma as significações que constrói, modificandoas continuamente em cada interação, seja com outro ser humano, seja com objetos.
} 
Algumas combinações foram feitas com a turma visando ao bom andamento das atividades. Apesar de haver organização dos tempos e espaços para o desenvolvimento das propostas, as crianças apresentam atitudes espontâneas e criam muitas possibilidades que enriquecem as formas de brincar e de interagir, por isso foi preciso estar atento às suas necessidades para realizar adequações. Era preciso conduzir os momentos de modo que houvesse abertura para essas interações, as quais são fundamentais e geradoras de aprendizado. As escolas de Educação Infantil possibilitam que laços afetivos sejam construídos, por isso as relações estabelecidas são extremamente importantes. Nesse sentido, a infância não se define como uma mera preparação para a vida adulta, na qual os professores estariam condicionando as crianças e, nesse movimento, intimidando-as em algumas circunstâncias.

No primeiro dia do projeto, as crianças foram orientadas sobre o uso da câmera e do meu smartphone. Com base na atividade de produção de fotografias que foi realizada antes de iniciar o trabalho, expliquei que não deveriam colocar os dedos na lente, bem como mencionei a necessidade de segurar com firmeza os equipamentos. As imagens que fizeram durante a caminhada foram mostradas para que pudessem compreender com mais clareza o que estava sendo solicitado. Nesse dia, as crianças plantaram sementes de alface, girassol e rabanete. Houve uma organização prévia do espaço em que essa atividade foi realizada: 12 embalagens vazias de produtos de limpeza foram cortadas, lavadas e enterradas até determinada altura para que ficassem firmes no solo e utensílios para o plantio foram disponibilizados para uso. Além disso, foi necessário usar substrato misturado à terra do pátio para auxiliar o cultivo. Convém ressaltar que as embalagens que foram reutilizadas haviam sido guardadas pelas funcionárias de limpeza da escola, evidenciando a importância que o apoio da equipe escolar possui para que as ações pedagógicas se efetivem. Quando as crianças chegaram ao local em que a atividade seria feita, algumas foram colocar terra e sementes nos recipientes enquanto outras fotografavam. Havia um revezamento entre elas para que pudessem se envolver no plantio e na produção de fotografias, pois havia apenas dois equipamentos para a captação das imagens (câmera fotográfica e smartphone). Depois que o plantio já havia sido realizado em todos os recipientes, algumas crianças foram filmadas por outras. Elas foram orientadas a contar o que haviam feito e expressar suas hipóteses a respeito do desenvolvimento das plantas. A seguir, há quatro fotografias produzidas pelas crianças que representam alguns momentos citados. 
Figura 1 - Fotografias produzidas no primeiro dia do projeto.
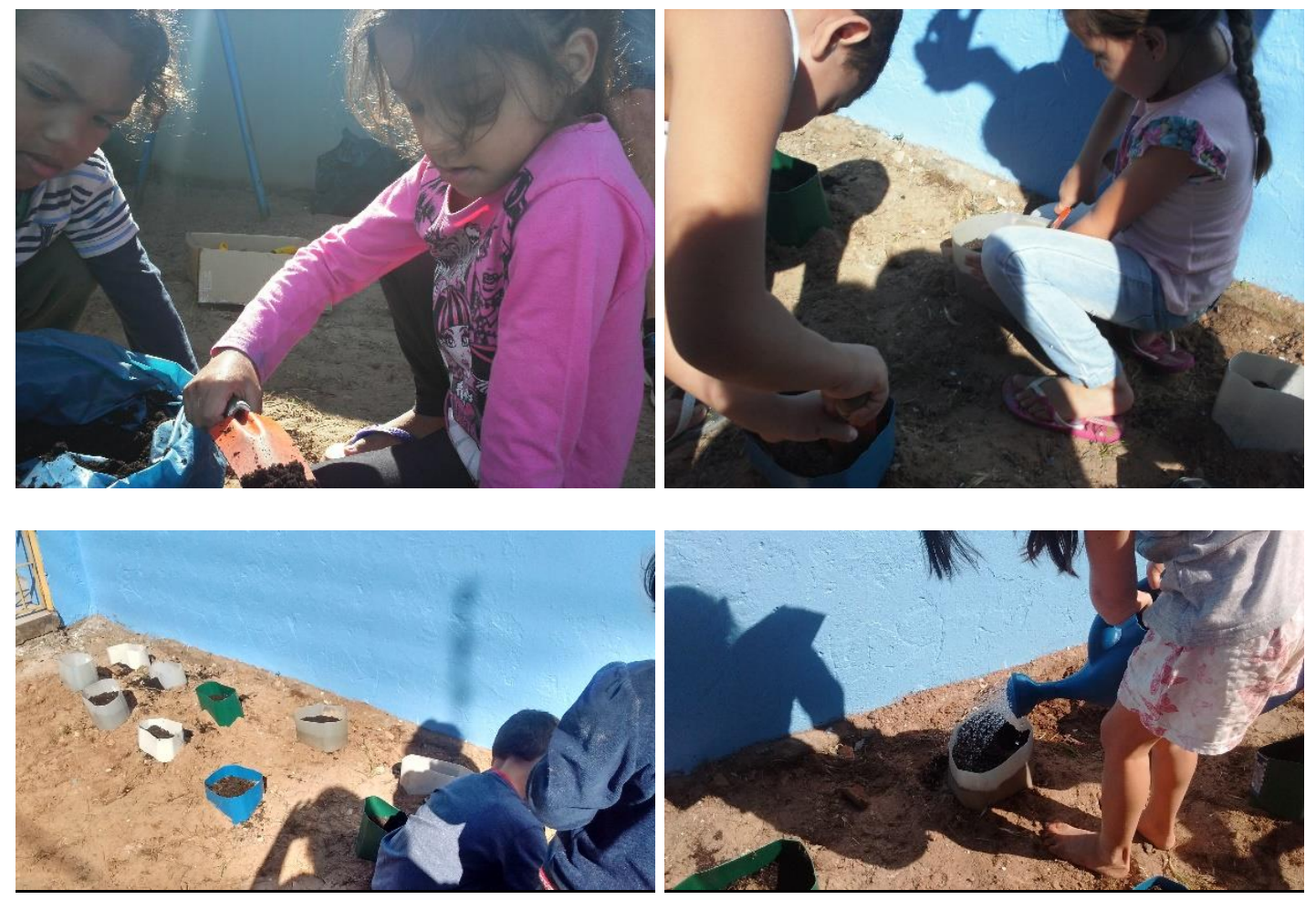

Fonte: Elaborado pelo autor.

O smartphone permitia que as imagens fossem visualizadas mais facilmente, por isso todos os vídeos foram gravados com ele. A câmera fotográfica foi utilizada exclusivamente para a produção de fotografias. As crianças necessitaram de auxílio tanto para a produção de fotografias quanto para a gravação dos vídeos, visto que estavam se apropriando do uso dessas tecnologias. Quando os vídeos foram gravados, parte da turma foi retirada do local para que não houvesse interferências. Se todas as crianças permanecessem juntas, haveria muito barulho. Devido ao interesse em interagir umas com as outras e com os espaços, foram levadas pela estagiária a outro pátio da escola para brincar com crianças de outras turmas.

Nas três semanas seguintes, as crianças foram observar o que havia acontecido com as plantas e fazer fotografias e filmagens. Uma vez por semana, elas analisavam as diferenças e semelhanças entre o desenvolvimento das plantas e, a partir disso, construíam conhecimentos que foram expostos de forma oral. Algumas citavam até as diferenças existentes em recipientes que haviam o mesmo tipo de planta. Um menino disse que um dos recipientes de rabanete era diferente de outro. Ao ser questionado sobre o motivo, respondeu que um tinha menos plantas. Essa percepção foi possível por causa da quantidade de sementes que foram colocadas no momento do plantio. As crianças costumavam enfatizar que as plantas maiores eram os 
girassóis. Uma menina disse que as folhas do rabanete tinham formato de coração e que as folhas do girassol eram tortinhas. Nesse período, a turma expressava o que observava e aquilo que poderia acontecer nas próximas semanas. A cada dia de desenvolvimento do projeto, um grupo de crianças era filmado, visto que a gravação de todas as crianças da turma seria inviável por causa do tempo que demandaria. Cada uma das fotografias a seguir foi captada pelas crianças em um dia diferente. Elas estão organizadas em ordem cronológica, da segunda à quarta semana.

Figura 2 - Fotografias produzidas no decorrer do projeto
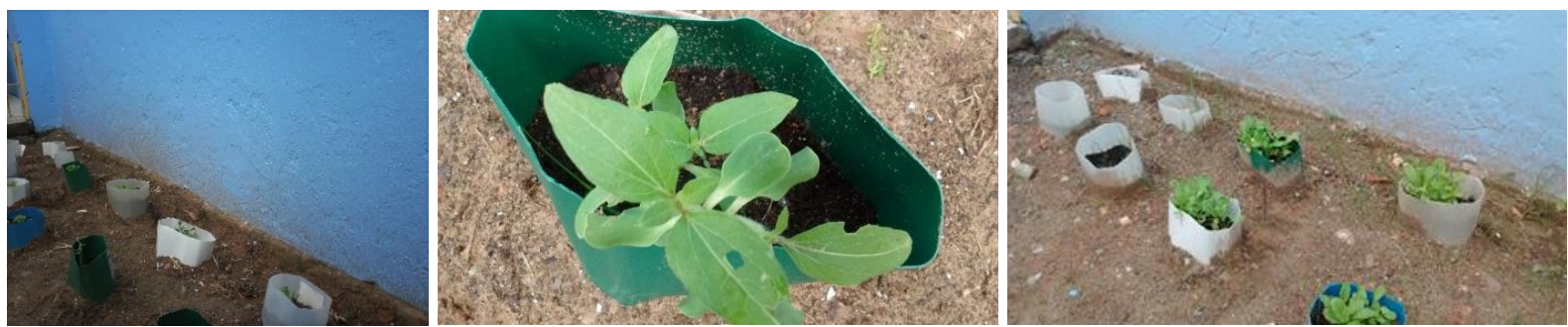

Fonte: Elaborado pelo autor.

A experimentação investigativa possibilita que se construam conhecimentos participando-se da sequência de acontecimentos e interpretando-a (OLIVEIRA, J., 2010). Sendo assim, a reflexão da turma envolveu a análise do que era observado e, a partir disso, eram formuladas e expressadas suas hipóteses sobre o desenvolvimento das plantas. Nesses momentos, busquei instigar as crianças por meio de perguntas.

Devido ao projeto ter sido realizado no turno da manhã, foi solicitado às professoras que atendiam à turma pela tarde que levassem algumas crianças para molhar as plantas quando necessário. Como foi um período que houve vários dias de chuva, a turma fez isso poucas vezes.

\section{Sistematização e divulgação das ações desenvolvidas}

O vídeo ${ }^{3}$ produzido com os materiais elaborados pela turma possibilitou analisar a produtividade da experiência, além de ser um meio de divulgação do projeto para a comunidade.

\footnotetext{
${ }^{3}$ Disponível em: https://www.dropbox.com/s/nhwj7ciobkfd6si/V\%C3\%ADdeo\%20projeto.mp4?dl=0. Acesso em: 3 ago. 2018.
}

Educação: Teoria e Prática/ Rio Claro, SP/ v. 31, n.64/2021. eISSN 1981-8106 e11[2021] 
Essa produção mostrou alguns materiais das crianças de forma contextualizada, de modo que fosse possível compreender o processo de desenvolvimento do projeto. Essa divulgação, realizada num perfil mantido pela escola em uma rede social ${ }^{4}$, permitiu que a comunidade escolar conhecesse as ações desenvolvidas. Desse modo, o vídeo, que contém fotografias e gravações produzidas pelas crianças, constitui-se num conjunto de informações compartilhadas que produz significados para seus espectadores ao mostrar os conhecimentos construídos pelas crianças no decorrer do acompanhamento das etapas de desenvolvimento das plantas. Esse retorno para os responsáveis pelas crianças participantes do projeto era indispensável, já que foi firmado o compromisso de que teriam conhecimento das propostas desenvolvidas quando o Termo de Consentimento Livre e Esclarecido foi assinado. Com esse documento, foi possível informar, antes do início do projeto, que ele estava vinculado aos estudos realizados em nível de pós-graduação e que, a partir dos dados gerados, uma pesquisa científica seria realizada. Além disso, foi estabelecida uma conversa sobre as intervenções pedagógicas que seriam desenvolvidas. Em virtude de o vídeo ter sido publicado no perfil de uma rede social, a divulgação abrangeu outras pessoas. Ele também foi publicado em um grupo dessa mesma rede social, no qual participam acadêmicos, professoras e tutoras do curso de especialização para que pudessem conhecer mais o projeto desenvolvido.

No dia em que o projeto foi encerrado - refiro-me ao projeto relacionado com o curso de especialização, visto que a turma continuou acompanhando o desenvolvimento das plantas e, consequentemente, construindo mais conhecimentos -, foi elaborado um informativo que relatava o que havia acontecido a cada semana (ver imagem a seguir). Foram utilizados um notebook e um projetor digital para produzi-lo. Antes de a turma contribuir para essa produção, foi definido um modelo adequado no software para a atividade e, a partir dele, as informações foram expostas com o auxílio das crianças. Elas escolheram imagens para compô-lo, assim como expressaram o que poderia ser escrito. Nessa atividade, organizei e dei formalidade às sugestões apresentadas pela turma. Desse modo, esse material, como também o vídeo, sistematizou as atividades do projeto. Alguns conhecimentos que foram construídos em relação à área ambiental estão registrados nesse informativo, como: as sementes de girassol são maiores do que as outras que foram usadas no plantio; as plantas semelhantes são das mesmas sementes; os girassóis são maiores do que os rabanetes e as alfaces; o caule do rabanete apresenta a cor

\footnotetext{
${ }^{4}$ Facebook.
} 
GENEHR, G.

roxa; entre outros. Além disso, foi citado que as fotos e os vídeos produzidos poderiam ser expostos.

Figura 3 - Informativo

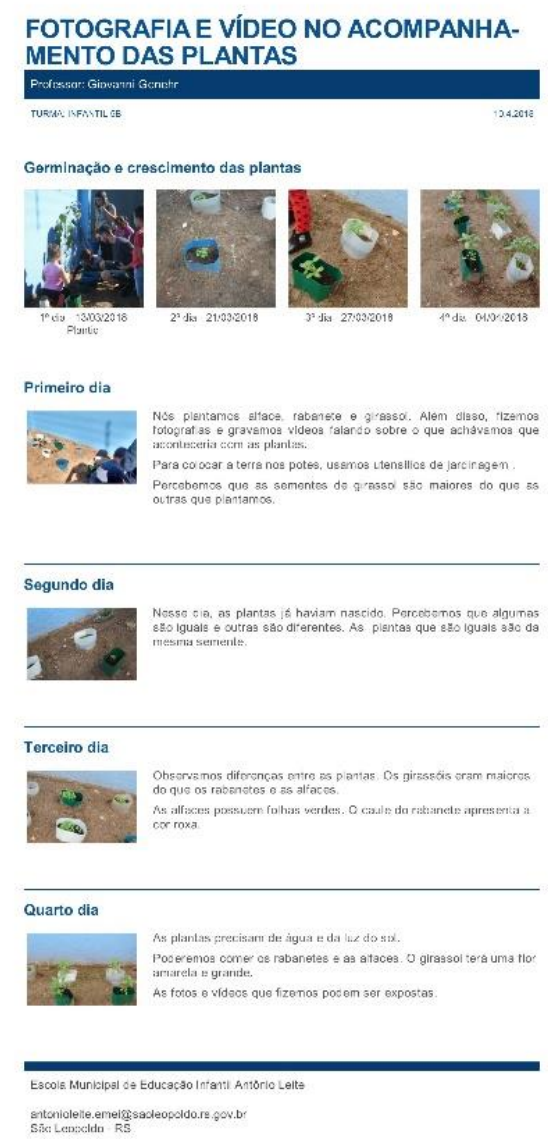

Fonte: Elaborado pelo autor.

Tanto no vídeo quanto no informativo foram identificadas as regularidades que possibilitaram analisar e interpretar os dados. De acordo com Sá-Silva, Almeida e Guindani (2009, p. 10), “A etapa de análise dos documentos propõe-se a produzir ou reelaborar conhecimentos e criar novas formas de compreender os fenômenos".

O projeto teve continuidade, pois o intuito não era que fossem feitas ações pontuais visando meramente ao cumprimento de atividades acadêmicas. Ele possuía potencialidades para outras intervenções, por isso optei por mantê-lo. Devido aos resultados positivos, propus o plantio para outra turma, que é composta, em sua maior parte, por crianças de 4 anos. Elas 
puderam observar o crescimento de suas plantas ao mesmo tempo em que acompanhavam o desenvolvimento das outras que já estavam maiores, pois os recipientes foram colocados no mesmo local e utilizadas as sementes de alface, rabanete e girassol também.

As atividades contribuíram para a compreensão de que há um processo de desenvolvimento das plantas e isso favorece, por exemplo, o entendimento de que as flores compradas em uma floricultura foram cultivadas antes de estarem disponíveis para serem adquiridas pelos clientes. Da mesma forma, propicia que se perceba que os alimentos passam por um período de cultivo antes de serem comercializados. Durante o projeto, as crianças puderam vivenciar esse processo em contato com a natureza, adquirindo aprendizagens sobre o meio ambiente e usando as tecnologias digitais para registrar e, posteriormente, retomar a sucessão de acontecimentos.

\section{Considerações finais}

As ações desenvolvidas nesse projeto possibilitaram que a turma aprendesse os conhecimentos científicos de forma contextualizada. Além disso, a metodologia educativa utilizada permitiu reestruturações no decorrer do projeto. As crianças tiveram momentos de construção coletiva e individual, expressaram-se por meio de registros fotográficos e de vídeo e conheceram o processo de germinação e de crescimento de três tipos de planta. Ao evidenciar motivação em observar as plantas e conseguir perceber semelhanças e diferenças entre elas, constatando a existência da biodiversidade, a turma demonstrou que atingiu os objetivos educativos que haviam sido definidos. As crianças ainda têm muito mais para explorar e aprender, tanto em relação à área ambiental, quanto ao uso de recursos tecnológicos, contudo destaca-se a importância que a criação e a expressão de suas hipóteses tiveram nesse processo de construção de conhecimentos, bem como o contato que tiveram com as tecnologias. Do mesmo modo, as tecnologias digitais foram fundamentais para a produção dos documentos analisados no decorrer da pesquisa, os quais favoreceram o exercício de reflexão sobre a docência.

Conforme foi demonstrado no decorrer deste texto, no intuito de responder à questão sobre o relacionamento da turma com as tecnologias digitais, as crianças, ao considerarem os vídeos produções que serão assistidas por outras pessoas, estabeleceram uma relação com o público usando, até mesmo, gestos. Enquanto professor pesquisador, percebi que as tecnologias 
digitais colaboraram na compreensão e no registro dos acontecimentos, permitindo que as crianças refletissem e analisassem o que observavam enquanto usavam os equipamentos e quando revisitavam os materiais produzidos. Assim, elas potencializam as aprendizagens e permitem que a documentação do processo de desenvolvimento das ações pedagógicas seja feita por meio do olhar infantil.

Apesar de não se terem equipamentos de ótima qualidade na escola, é importante destacar que apenas os materiais não são suficientes para o desenvolvimento de propostas que auxiliem as crianças na construção de aprendizagens. Eles são de extrema importância, porém o diferencial do trabalho estará fortemente atrelado ao uso pedagógico e intencional das tecnologias. A formação dos professores para que propiciem projetos eficientes e contextualizados favorece, portanto, a qualidade do ensino escolar.

Ao vivenciar o uso das tecnologias com as crianças tive a oportunidade de articular os conhecimentos acadêmicos com as ações desenvolvidas na escola. Pretendo continuar utilizando-as em novas propostas, visto que possuem um grande potencial para qualificar os projetos pedagógicos.

\section{Referências}

BOCCATO, V. R. C.; FUGITA, M. S. L. Discutindo a análise documental de fotografias: uma síntese bibliográfica. Cadernos BAD, n. 2, 2006. Disponível em: https://bad.pt/publicacoes/index.php/cadernos/article/download/794/793. Acesso em: 26 maio 2018.

BRASIL. Ministério da Educação. Secretaria de Educação Básica. Secretaria de Educação Continuada, Alfabetização, Diversidade e Inclusão. Conselho Nacional da Educação.

Diretrizes Curriculares Nacionais Gerais da Educação Básica. Brasília: MEC, SEB, DICEI, 2013. Disponível em: http://portal.mec.gov.br/docman/julho-2013-pdf/13677diretrizes-educacao-basica-2013-pdf/file. Acesso em: 24 jun. 2018.

CORDEIRO, S. da S.; ALMEIDA, C. L. de. Aprendizes de caranguejo: produção de vídeos com crianças na Educação Infantil. Práxis Educacional, Vitória da Conquista, v. 8, n. 12, p. 199-217, jan./jun. 2012. Disponível em: https://periodicos2.uesb.br/index.php/praxis/article/view/696. Acesso em: 17 jun. 2018.

FRESCHI, M.; RAMOS, M. G. Unidade de Aprendizagem: um processo em construção que possibilita o trânsito entre senso comum e conhecimento científico. Revista Electrónica de Enseñanza de las Ciencias, v. 8, n. 1, p. 156-170, 2009. Disponível em: http://reec.uvigo.es/volumenes/volumen8/ART9_Vol8_N1.pdf. Acesso em: 27 maio 2018. 
GALIAZZI, M. do C. Construindo caleidoscópios: organizando unidades de aprendizagem. ANPED SUL, Mesa-redonda n. 97 - Eixo temático 1 - Formação de Educadores. Disponível em:

http://www.portalanpedsul.com.br/admin/uploads/2002/Didatica,_curriculos_e_processos_de _escolarizacao/Mesa_Redonda/03_09_38_m97-817.pdf. Acesso em: 8 abr. 2017.

HORN, C. I. Os saberes das crianças no contexto escolar da Educação Infantil. In:

MARQUETI, M. T.; SÁ, R. A. de. A identidade docente e o uso das tecnologias e mídias digitais na escola à luz do pensar complexo. Rev. Diálogo Educ., Curitiba, v. 17, n. 51, p. 167-183, jan./mar. 2017. Disponível em:

www2.pucpr.br/reol/index.php/dialogo?dd99=pdf\&dd1=16535. Acesso em: 27 maio 2018.

MUNHOZ, A. V. et al. (org.). Diálogos na pedagogia: coletâneas. v. 3 - Infância e outros temas. Lajeado: Editora UNIVATES, 2012.

OLIVEIRA, J. R. S. de. Contribuições e abordagens das atividades experimentais no ensino de ciências: reunindo elementos para a prática docente. Acta Scientiae, Canoas, v. 12, n. 1, p. 139-153, jan./jun. 2010. Disponível em: http://w3.ufsm.br/laequi/wpcontent/uploads/2015/03/contribui\%C3\%A7\%C3\%B5es-e-abordagens-de-atividadesexperimentais.pdf. Acesso em: 1 jul. 2018.

OLIVEIRA, Z. de M. R. de. O currículo na Educação Infantil: o que propõem as novas Diretrizes Nacionais? In: I SEMINÁRIO NACIONAL: CURRÍCULO EM MOVIMENTO PERSPECTIVAS ATUAIS, 2010, Belo Horizonte. Anais [...] Belo Horizonte, 2010.

Disponível em:

http://portal.mec.gov.br/index.php?option=com_docman\&view=download\&alias=7153-2-1curriculo-educacao-infantil-zilma-moraes\&category_slug=dezembro-2010pdf\&Itemid=30192. Acesso em: 17 jun. 2018.

PIMENTA, S. G. Formação de professores: saberes da docência e identidade do professor. Nuances, v. 3, p. 5-14, set. 1997. Disponível em: https://edisciplinas.usp.br/pluginfile.php/1287224/mod_resource/content/1/Pimenta_Form\%2 0de\%20profs\%20e\%20saberes\%20da\%20docencia.pdf. Acesso em: 24 jun. 2018.

SÁ-SILVA, J. R.; ALMEIDA, C. D. de; GUINDANI, J. F. Pesquisa documental: pistas teóricas e metodológicas. Revista Brasileira de História \& Ciências Sociais, ano 1, n. 1, p. 1-15, jul. 2009. Disponível em: https://www.rbhcs.com/rbhcs/article/download/6/pdf. Acesso em: 1 jul. 2018.

Recebido em: 01/09/2018

Revisado em: 01/04/2020

Aprovado em: 05/02/2021

Publicado em: 15/03/2021 